\title{
SEISMIC ASSESSMENT OF MASONRY TOWERS: THE CASE OF CASTELLUM AQUAE SYSTEM IN POMPEII
}

\author{
M. SALVALAGGIO ${ }^{1}$, V. SABBATINI ${ }^{2}$, F. LORENZONI ${ }^{3 *}$, M.R. VALLUZZI ${ }^{1}$ AND \\ H. WENLIUHAN ${ }^{4}$ \\ ${ }^{1}$ Department of Cultural Heritage (DBC) \\ Università degli Studi di Padova \\ Piazza Capitaniato 7, 35139 Padova, Italy \\ e-mail: matteo.salvalaggio@unipd.it,mariarosa.valluzzi@unipd.it
}

\author{
${ }^{2}$ Department of Architecture \\ Università degli Studi Roma Tre \\ Largo Giovanni Battista Marzi 10, 00153 Roma, Italy \\ e-mail: valerio.sabbatini@uniroma3.it \\ ${ }^{3}$ Department of Geoscience \\ Università degli Studi di Padova \\ via Gradenigo 6, 35131 Padova, Italy \\ e-mail: filippo.lorenzoni@unipd.it \\ ${ }^{4}$ Earthquake Engineering Research \& Test Center \\ Guangzhou University \\ Guang Yuan Zhong Rd. 248, 510405 Guangzhou, China \\ e-mail:wlh-gd@gzhu.edu.cn
}

Keywords: historical masonry, towers, Pompeii, finite element modeling

\begin{abstract}
The archaeological site of Pompeii is an extraordinary evidence of Roman architectural heritage which comprehends a large number of masonry constructions, buried after the Vesuvius eruption in 79 AD. They were discovered in the XVIII century when renewed cultural interest induced numerous archaeological excavations. In this scenario, the remains of the Roman aqueduct system, i.e. Castellum Aquae system [1], includes a series of approximately $6 \mathrm{~m}$ height masonry water towers (WTs). Among the fourteen surveyed, four free-standing towers (i.e. no. 1, 2, 3 and 4) have been investigated in 2015 by means of nondestructive techniques (sonic pulse velocity tests, ground penetrating radar (GPR), ambient vibration tests), aimed at gathering information on the constructive systems and the current conservation state, as well as data on the overall dynamic behaviour. According to the on-site inspections outcomes, 3D finite element models of the towers were constructed and calibrated on the results of operational modal analysis (OMA) [2]. The model updating procedure was able to describe and simulate the soil-structure interaction, introducing a Winkler elastic soil model, and to define the elastic parameters of masonry.

This paper describes the seismic vulnerability assessment of the four WTs, considering both
\end{abstract}


equilibrium capacity and material strength, performing analytical kinematic analyses and numerical finite element modelling.

Aiming at improving the previous studies [3], equivalent modal parameters (i.e. natural frequencies and mode shapes) are used to calibrate analytical models and furtherly refine FE model updating. The numerical models were generated using DIANA software [4], implementing a nonlinear constitutive law for masonry material, i.e. total strain crack model. Afterwards, sensitivity analyses are performed to calibrate both the elastic properties of materials and the Winkler springs' stiffness. Eventually, analytical kinematic approach and FE pushover analyses (with uniform and modal force distribution) are executed to assess the seismic vulnerability of the WTs, according to Italian code [5].

Results of the analyses are presented and discussed. The study was the occasion to compare the results of kinematic and numerical procedures applied to archaeological structures. The results report the FE approach as more conservative than kinematic model. Thus, the importance to adopt a combined global (numerical) and local (limit analysis) approach in the assessment of archaeological structures is stressed.

\section{INTRODUCTION}

During the archaeological excavation of Pompeii brick and stone masonry water towers, part of the ancient aqueduct system, were discovered. Water towers are located throughout the city and have different heights with the scope of providing water to the whole city. Castellum Aquae, it controlled the water fl water towers (as shown reduction [7]. Water tow are connected to other buildings. Water towers $\mathrm{BC}$, before the reconstruction caused by the
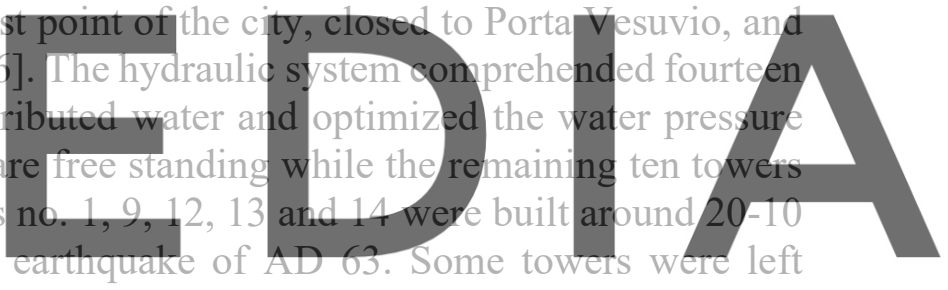
uncompleted because of the sudden Vesuvius's eruption of 79 AD that completely buried the Register fafyfree at https//www.scipedia.com to download the version without the watermark

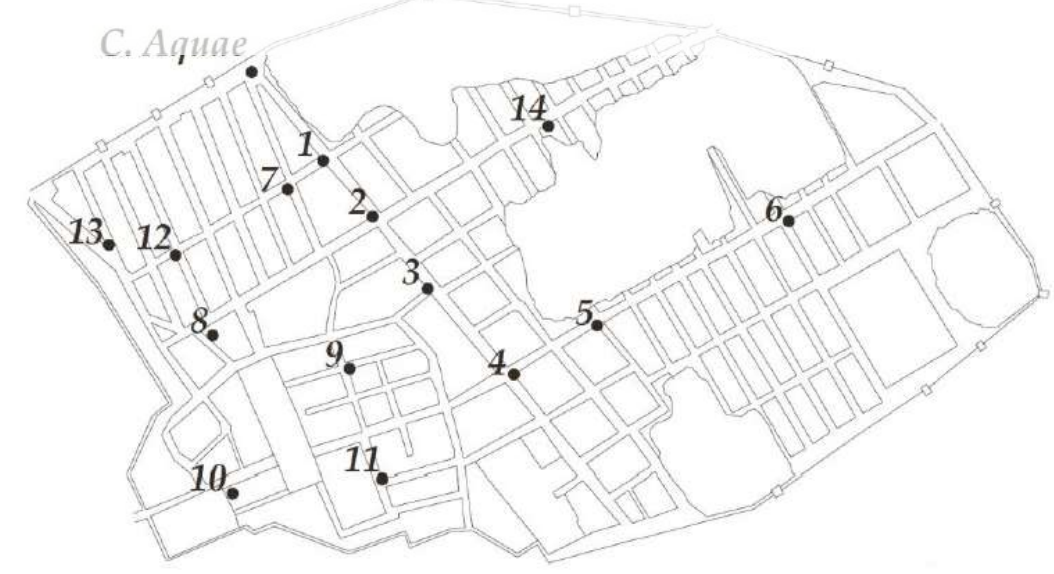

a)

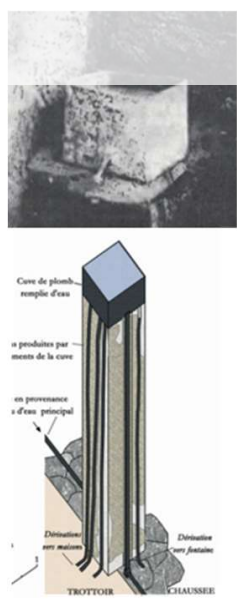

b)

Figure 1: a) Water towers layout in the Pompeii site[7]; b) original layout of the water tower with the container at the top [7] 
According to the archaeological studies, water containers were once placed on top of the WTs to store water [8]. The researches hypothesized that the containers had been part of the water distribution system in the city and used to operate in their time. Olsson [9] advocates the concept of an ancient urban water distribution system and proposed a plausible condition of the original Containers; they are made of lead, the base dimensions are slightly smaller than the those of the water towers, and the height is approximately $1 \mathrm{~m}$.

\section{SURVEY AND ON-SITE INSPECTIONS}

The water towers are at least $6 \mathrm{~m}$ tall with quadrangular base sections of about $1.2 \mathrm{~m}$ wide. Part of the masonry volume was removed to place the pipes that carried water from the top lead container to the surrounding buildings. Water tower no. 1 (later called WT1) was built with Nocera tuff masonry; water tower no. 2 (WT2) and no. 3 (WT3) are made of clay bricks with a discontinuity of material in tower no. 2 at $4.3 \mathrm{~m}$ from the ground, water tower no. 4 (WT4) is composed of three layers of Sarno limestone from the ground level to $1.6 \mathrm{~m}$ in height, Nocera tuff from $1.6 \mathrm{~m}$ to $4 \mathrm{~m}$ and yellow tuff up to the top. The geometric survey is reported in Figure

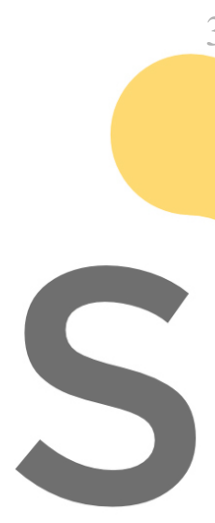
3.

a)
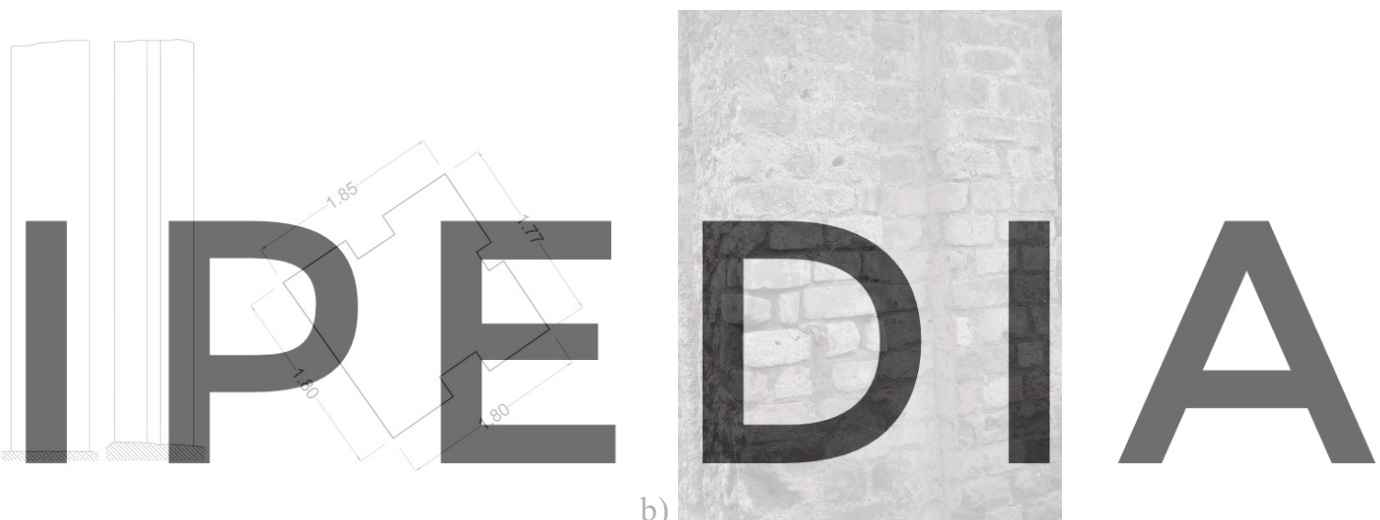

a)

Register for free at https//www.scipedia.com to download the version without the watermark

\section{Figure 2. a) Geometric survey of WT1 [7]; b) masonry detail of WT1.}

Visual inspections and on-site non-destructive tests were performed by the authors on the four water towers in June 2015. Sonic tomographic tests and ground penetrating radar (GPR) were executed to investigate masonry sections and identify the presence of inner cores and voids/discontinuities. Moreover, dynamic identification tests were carried to characterize the dynamic behaviour of the four towers [2]. Ambient vibrations tests (AVT) and output-only identification techniques were used to extract modal parameters in terms of natural frequencies, damping ratios and mode shapes. Tests were carried out through the recording of three different acceleration time-histories in 6 points for each tower, according to the analysis and interpretation of the expected mode shapes.

The results of dynamic testing and modal analysis are presented in the following table. The dynamic behavior of the four WTs can be related to an inverted pendulum with the first 2 bending modes along the principal horizontal directions (frequencies between $2.6 \mathrm{~Hz}$ and 3.1 $\mathrm{Hz}$ ), 1 torsional mode (frequency between $11 \mathrm{~Hz}$ and $17 \mathrm{~Hz}$ ) and 2 second order bending modes (frequency between $14 \mathrm{~Hz}$ and $17 \mathrm{~Hz}$ ). 
Table 1. Natural frequencies of the four WTs identified through AVTs

\begin{tabular}{ccccc} 
& WT1 & WT2 & WT3 & WT4 \\
\hline Mode no. & $f[\mathrm{~Hz}]$ & $f[\mathrm{~Hz}]$ & $f[\mathrm{~Hz}]$ & $f[\mathrm{~Hz}]$ \\
\hline 1 & 2.979 & 2.783 & 2.686 & 3.076 \\
\hline 2 & 3.174 & 3.125 & 3.320 & 3.125 \\
\hline 3 & 16.89 & 10.94 & 12.23 & 14.01 \\
\hline 4 & 17.09 & 14.4 & 15.48 & 15.04 \\
\hline 5 & 17.33 & 15.48 & 16.31 & 15.19
\end{tabular}

\section{KINEMATIC ANALYSIS}

The seismic vulnerability assessment of the four water towers was preliminary assessed through the limit analysis method, according to kinematic approach suggested by the Italian Code [5]. Towers were modelled as monolithic rigid blocks, able to rotate on a plastic hinge at the base. The rotation pole translation due to base compressive stresses was calculated, whereas no tensile strength was considered for masonry.

Different collapse mechanisms were studied considering both global overturning (for WT1, WT2, WT3 and WT4) and local overturning (for WT2 and WT4), as shown in Figure 3, due to

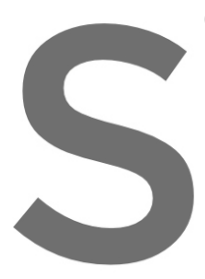
different construction phases,
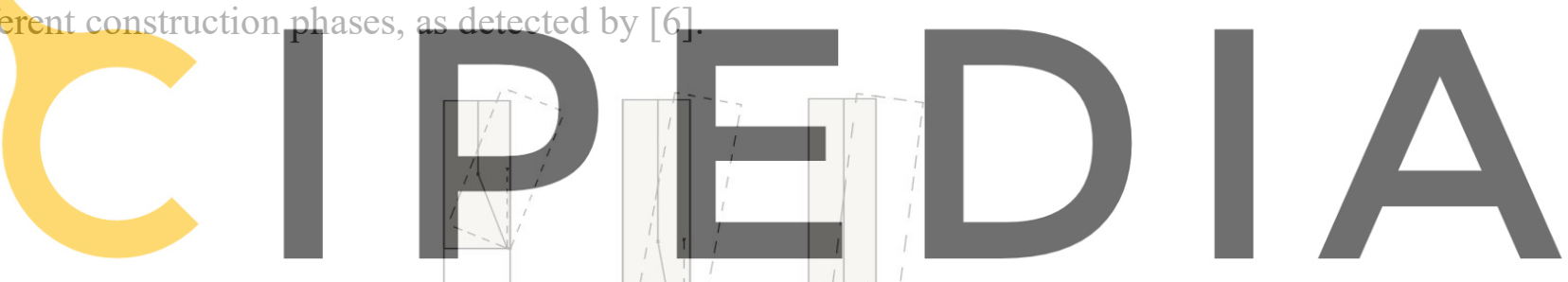

Register for free at https//www.scipedia.com to download the version without the watermark

Figure 3. Analyzed collapse mechanisms for WT4

Table 2. Mechanical properties of masonry for the four WTs

\begin{tabular}{|c|c|c|c|c|c|c|}
\hline & & & Tuff & Solid Brick & Calculation factors & \\
\hline Mass density & $\rho$ & {$\left[\mathrm{kN} / \mathrm{m}^{3}\right]$} & 16 & 18 & Confidence factor & 1.35 \\
\hline \multirow[t]{2}{*}{ Compressive strength } & $\mathrm{f}_{\mathrm{m}}$ & {$\left[\mathrm{N} / \mathrm{mm}^{2}\right]$} & $1.4 \div 2.4$ & $2.4 \div 4.0$ & Material safety coefficient $\gamma_{\mathrm{m}}$ & 2 \\
\hline & & & & & Behaviour factor $\mathrm{q}$ & 2 \\
\hline
\end{tabular}

The mechanical characteristics of materials have been obtained from the Italian code, which provides a range of values for various masonry typologies. Since the inspections phase was performed only through non-destructive testing technique a limited knowledge level was achieved (KL1), corresponding to a confidence factor $(\mathrm{CF}=1.35)$ to be applied to the material 
mechanical properties. In addition, a safety coefficient of 2 was applied as well as a behavior factor of 2 for the seismic vulnerability assessment (Table 3).

Geological inspections (MASW Multichannel Analysis of Surface Waves) were performed to characterize the soil type for seismic purposes, i.e. determination of the velocity profile for shear waves (Vs). According to the results a soil category $\mathrm{C}$ was assigned.

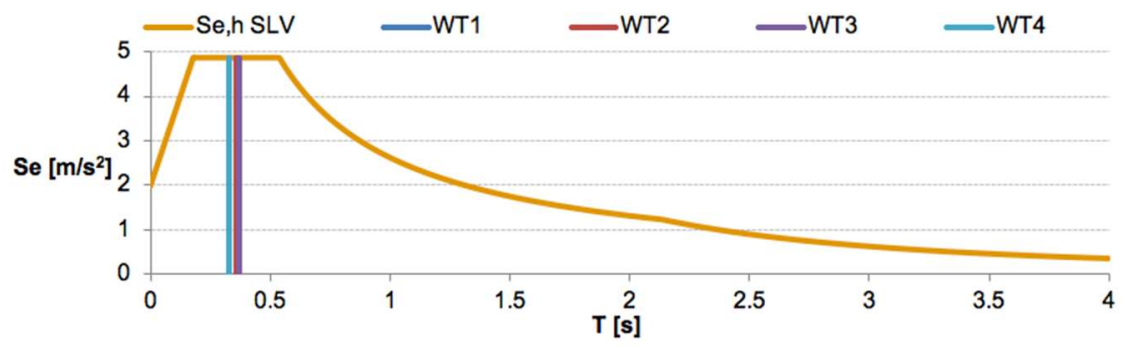

Figure 4 Life-safety limit state elastic response spectrum.

The seismic action used for the assessment of the WTs is defined by the seismic hazard parameters for the site of Pompeii (ag=0.133g for an earthquake return period of 474 years) and the related elastic response spectrum, defined at the Life Safety limit state (Figure 4). Is it possible to notice that the first two principal bending modes of the towers identified by AVTs have a period between $0.3 \mathrm{~s}$ and $0.4 \mathrm{~s}$, which correspond to the maximum amplifichtion in the
response spectrum (horizontal branch of the diagram in Figure 4 ).
The seismic vulnerability of the WXs was determinec in the current state and in the original
state, with the presence of the xater container at the top. This configuration was useful to
investigate its role in the reduction of the seismic capacity of the structures. Water container was simulated adding a mass at the top of the tower, considering different level of the water Register for free a completely full, half and empty to download the version without the watermark The capacity/demand ratio $\zeta_{\mathrm{E}}$ was calculated for each configuration and the results are presented in the following histograms.

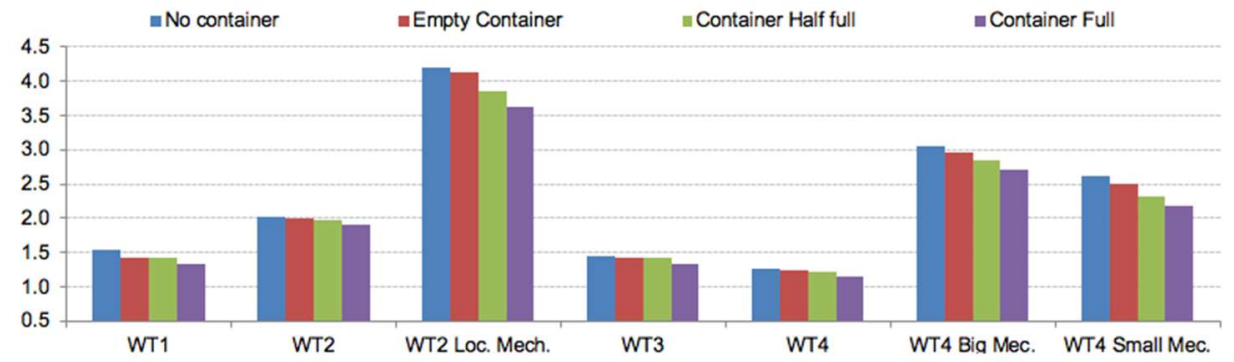

Figure 5. Capacity/demand ratio $\zeta_{\mathrm{E}}$ for the four WTs considering different collapse mechanisms

It is clear that for each WT the global overturning with the formation of the hinge at the base is the most vulnerable collapse mechanism. WT4 among the others is the most vulnerable structure $\left(\zeta_{\mathrm{E}}=1.27\right)$, while WT2 is the less vulnerable one $\left(\zeta_{\mathrm{E}}=2\right)$. As expected, the presence of the water container at the top reduces the capacity of the structure of a percentage between $4.5 \%$ 
and $11.3 \%$.

The main parameters involved in the definition of the seismic vulnerability of the water towers were further investigated. Parametric analyses have been performed changing and assessing the following factors: (i) return period and PGA, (ii) behaviour factor q and (iii) soil category. Results are reported in the following graphs.
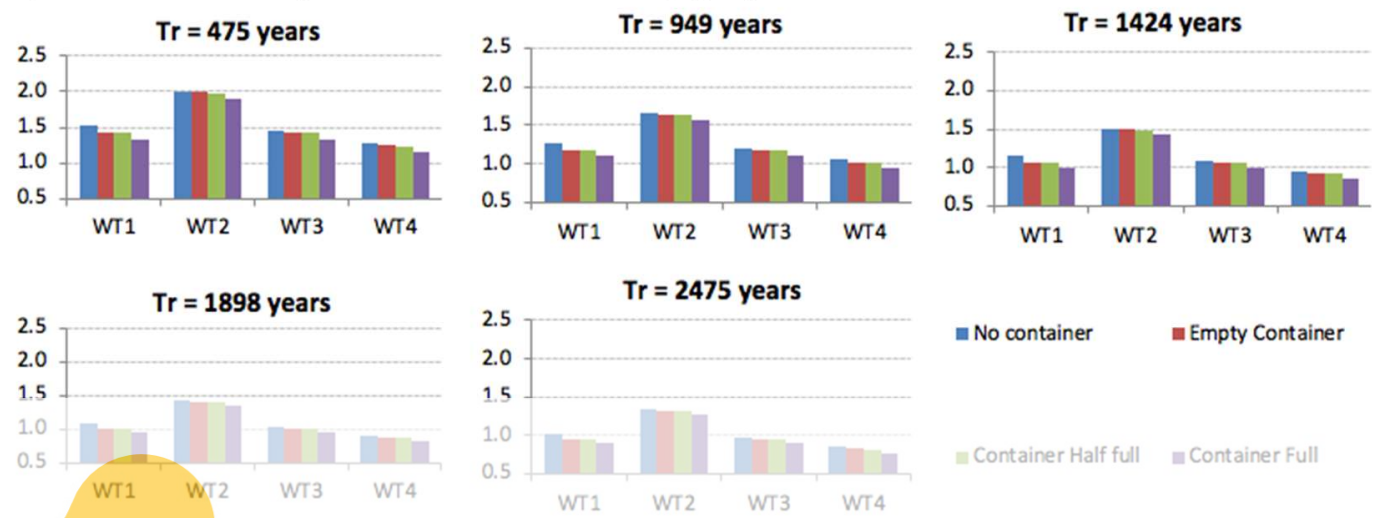

No container $\quad$ Empty Cont ainer

Figure 6. Capacity/demand ratio $\zeta_{\mathrm{E}}$ for the four WTs varying the earthquake return period
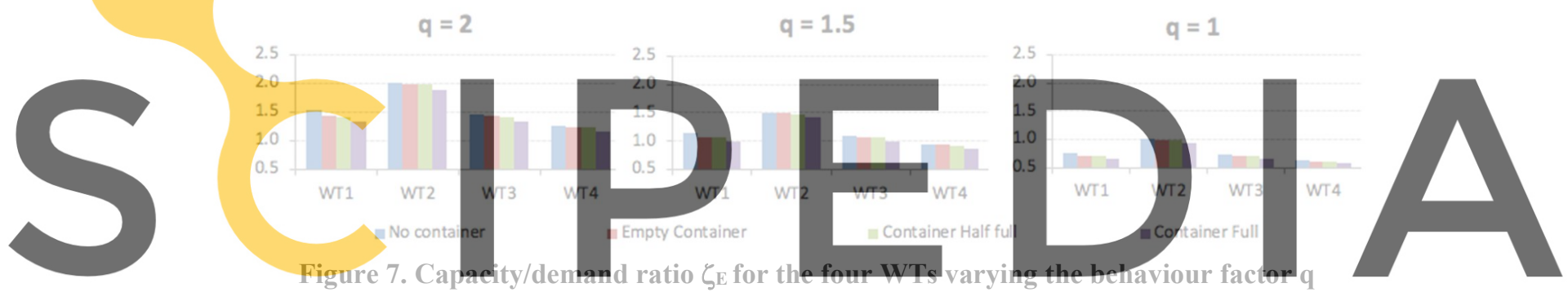

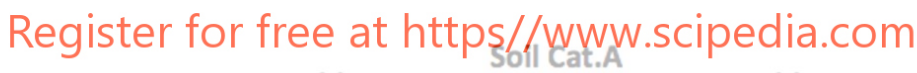
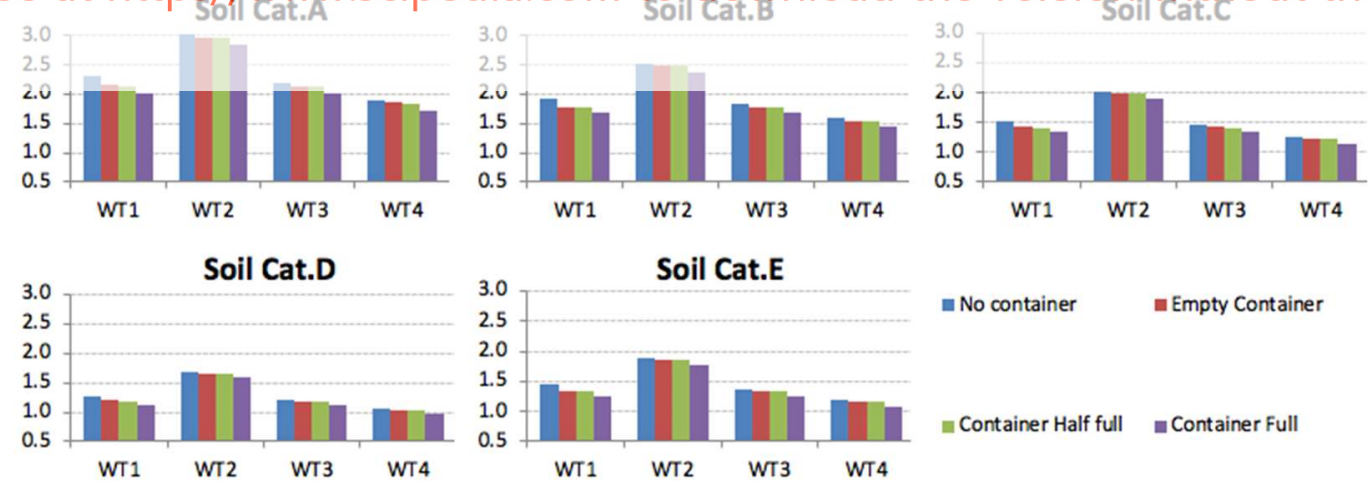

- No container $\quad$ Empty Container

Figure 8. Capacity/demand ratio $\zeta_{E}$ for the four WTs varying the soil type

The study of the collapse mechanisms confirmed that the global overturning of the WTs is the most vulnerable collapse mechanism. The analyses highlighted a higher vulnerability of the WTs with the full water container at the top due to an increase of the overturning moment caused by an additional mass. The most vulnerable tower, according to limit analysis, is WT4, 
while the less vulnerable is WT2, able to satisfy the seismic demand for a return period of 2475 years (PGA=0.2196), the highest suggested by Italian code.

\section{FINITE ELEMENT ANALYSIS}

Numerical analyses were carried out according to finite element approach, with the DIANA FEA 10.3 code [4]. The four towers have been discretized through $15 \mathrm{~cm}$-size 8-noded (HX24L) and 6-noded (TP18L) linear brick elements, with a number of nodes varying from 3700 to 8300 among the towers models (Figure 9).

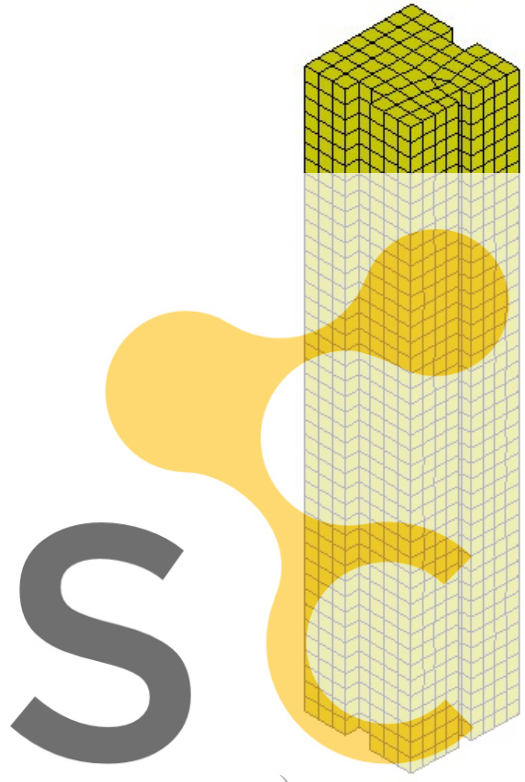

a)

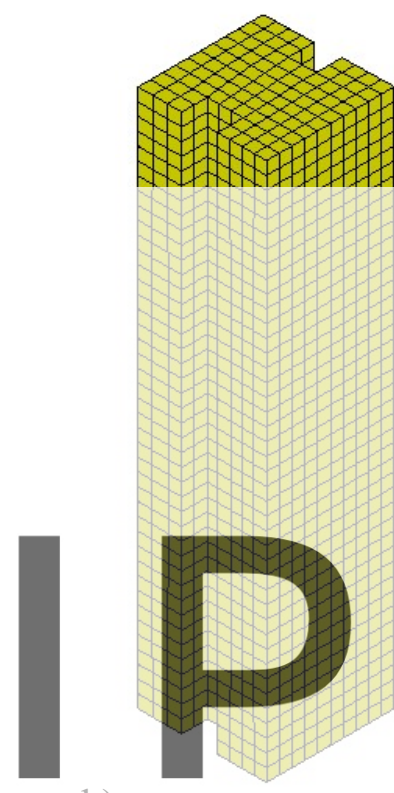

b)

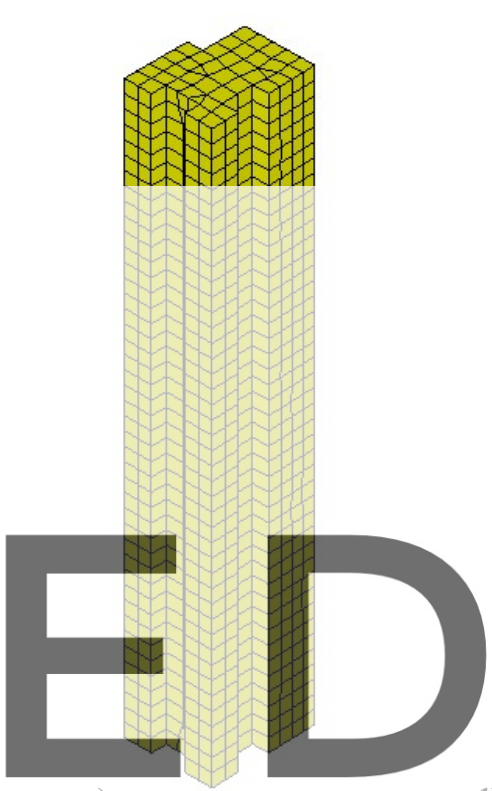

c)

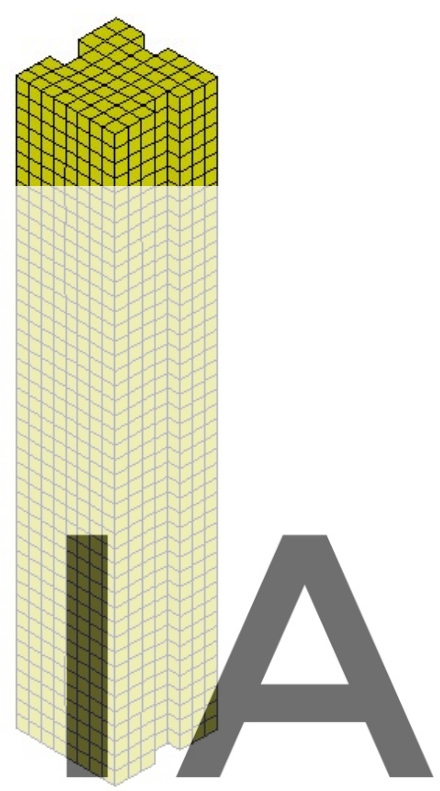

d)

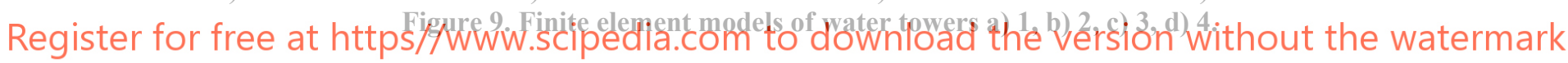

The structural behaviour of a 2000 years old tower is seriously affected by its conservation state, which has been investigated through the described NDT. Thus, on the basis of the work described in [2], the finite element model of water tower no. 1 has been furtherly updated, since the experimental dynamic data collected show a good match with the expected ones, revealing a good conservation status among the four structures. As noticed in [2], rigid constraints at the base are boundary conditions not compatible with an optimal model updating. Thus, according to Winkler model for soil, SP1TR spring elements along main three directions were applied at the base nodes in order to simulate the soil-structure interaction (Figure 10).

The values of modulus of subgrade reaction were based on the ones reported in [9]. The stiffness of the base springs is obtained as the product of modulus of subgrade reaction and influence area of each node. The simulation of soil-structure interaction was furtherly refined considering different influence areas according to the position of nodes in the base (inner section, edge, corner). 


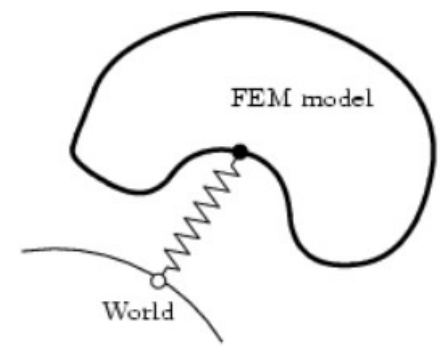

a)

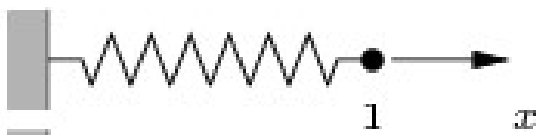

b)

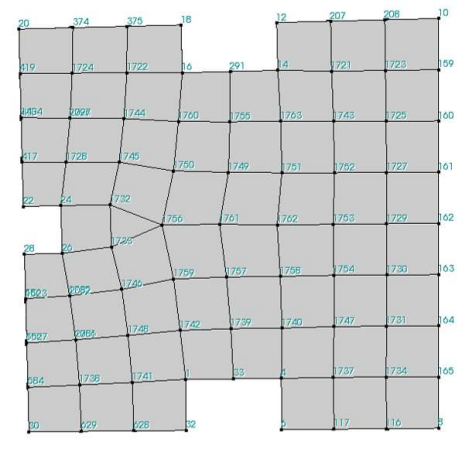

Figure 10. a) One-node SP1TR spring scheme [4]; b) layout of base springs.

The numerical study was scheduled and performed as follows:

i) Based on the work reported in [4], a sensitivity analysis of the linear properties affecting mode shapes (i.e., mass density and elasticity modulus) have been performed on water tower no. 1, in order to define an updated numerical model;

ii) Once the linear properties of WT1 structural model have been calibrated, a sensitivity analysis aimed at studying the nonlinear properties (i.e. compressive strength, tensile
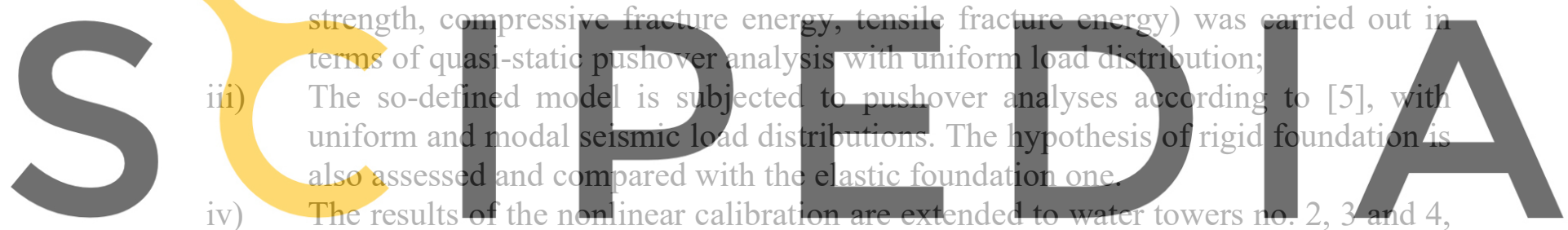

which are analyzed with the same method. Seismic vulnerability assessment of the

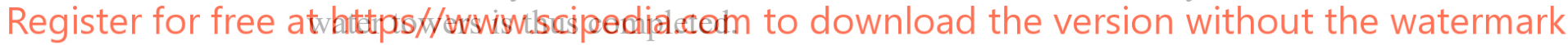

\subsection{Sensitivity analysis of limear dymamic behavior}

The modulus of subgrade reaction is a parameter which takes into account the soil characteristics and the geometry of the foundation system. Unfortunately, neither is available in this case, since geotechnical investigations were carried out only outside the archaeological site and the foundation systems have not been surveyed. Therefore, reference value of the modulus of subgrade reaction, deduced from the one reported in scientific literature [9], were implemented $\left(\mathrm{k}_{\mathrm{s}}=5 \cdot 10^{10} \mathrm{~N} / \mathrm{m}^{3}\right)$.

As reported by [10], stiffnesses along vertical $(\mathrm{Z})$ and horizontal $(\mathrm{X}, \mathrm{Y})$ directions are not constant, especially for historical structures. Thus, sensitivity analysis were carried out, keeping fixed the vertical stiffness $Z$ or the horizontal ones $X$ and $Y\left(\right.$ at $5 \cdot 10^{10} \mathrm{~N} / \mathrm{m}^{3}$ ). Frequency discrepancy $D_{f}$ percentages between experimental and numerical mode shapes, in function of vertical and horizontal springs stiffnesses, are reported in Figure 11. 


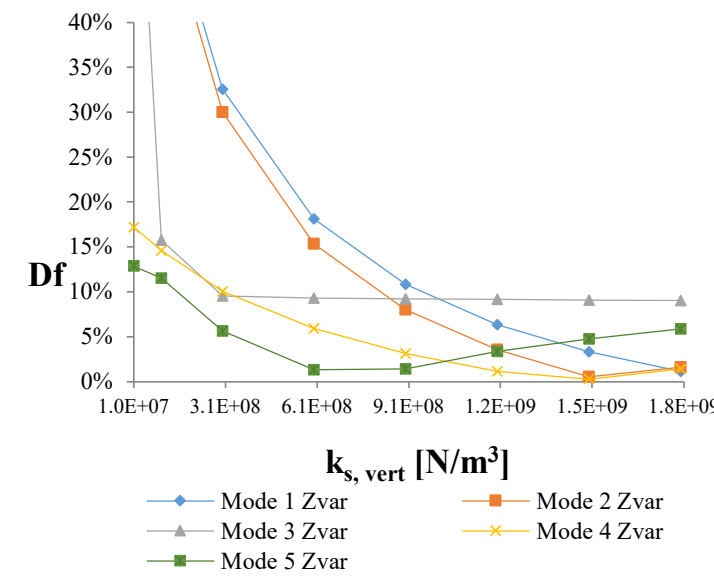

a)

Figure 11. Frequency discrepancy in function of bases

$$
\text { stiffness }
$$

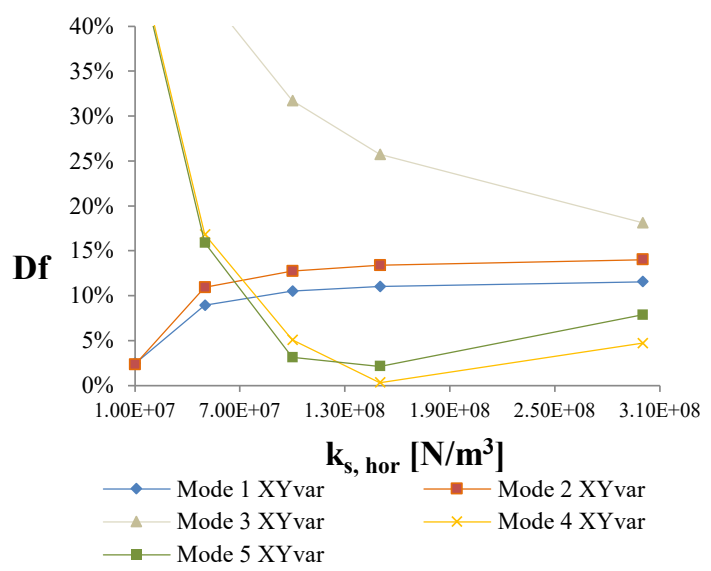

b)

Based on the results of the sensitivity analysis, linear properties of the numerical models were selected as follows: mass density $w=16.7 \mathrm{kN} / \mathrm{m}^{3}$, Young's modulus $E=1050 \mathrm{MPa}$, Poisson's ratio $v=0.2$, whereas modulus of subgrade reaction was fixed equal to $\mathrm{k}_{\mathrm{s}, \text { vert }}=$ $1.5 \cdot 10^{9} \mathrm{~N} / \mathrm{m}^{3}$ for vertical springs, whereas horizontal ones are fixed as one-fifth of them

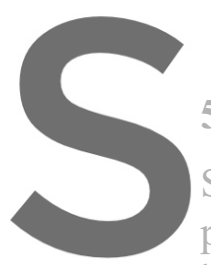
$\left(\mathrm{k}_{\mathrm{s}, \mathrm{hor}}=3 \cdot 10^{8} \mathrm{~N} / \mathrm{m}^{3}\right)$

5.1 Pushover analysis

Seismic vulnerability as pushover analysis). Non
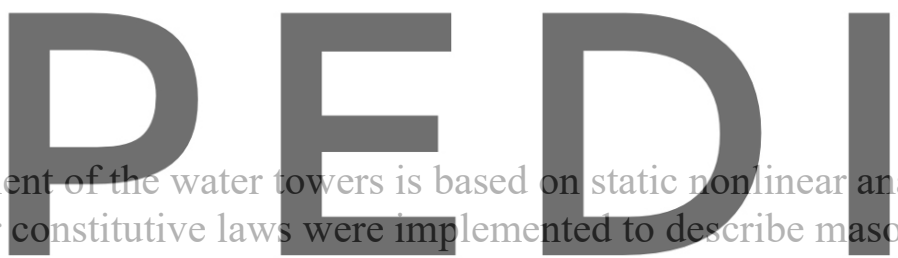

behavior, i.e. the so-called total strain based crack model. A parabolic compressive law and an

Register foxpential Gaftening tensile law are described by strengthap fracture energyvalues. Reference value were taken from Italian codes [5] and scientific literature. Tensile strength is derived from Italian code shear strength through Turnsek-Cacovic law. The strength values are obtained after the application of safety coefficient $\gamma=2$ and a confidence factor $\mathrm{FC}=1.35$ [5]. The model properties are reported in Table 3.

Table 3. Mechanical parameters of structural material

\begin{tabular}{cccccccc}
\hline Element & $\mathbf{E}[\mathbf{M p a}]$ & $\boldsymbol{\rho}\left[\mathbf{K N} / \mathbf{m}^{3}\right]$ & $\boldsymbol{v}$ & $\mathbf{f}_{\mathbf{c}}[\mathbf{M P a}]$ & $\mathbf{G}_{\mathbf{f c}}[\mathbf{N} / \mathbf{m m}]$ & $\mathbf{f}_{\mathbf{t}}[\mathbf{M P a}]$ & $\mathbf{G}_{\mathrm{ft}}[\mathbf{N} / \mathbf{m m}]$ \\
\hline $\mathrm{WT} 01$ & 1050 & 17 & 0.2 & 0.52 & 0.05 & 0.015 & 0.01 \\
\hline
\end{tabular}

The results of the analyses are elaborated in terms of base shear-displacement capacity curves, reported in Figure 12a. The typical collapse configuration of water tower no. 1 is observable in Figure 12b. 


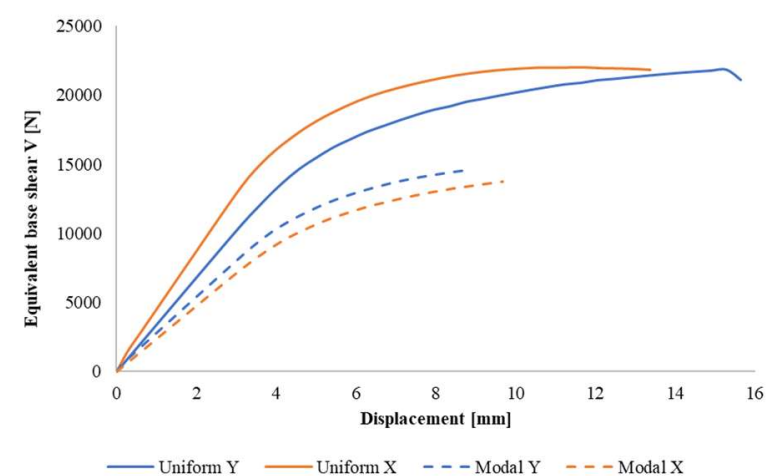

a)

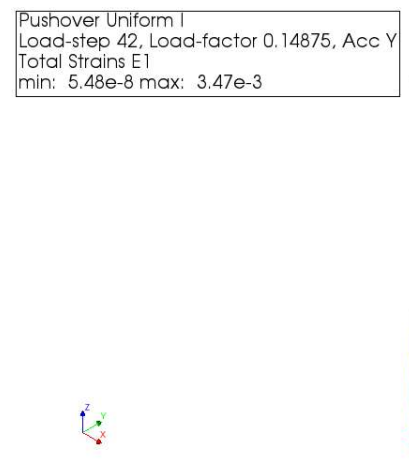

b)

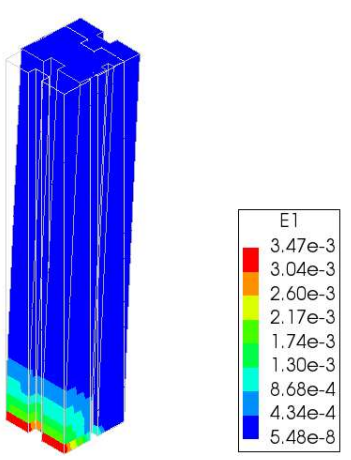

Figure 12. a) Capacity curves of water tower no. 1 for uniform and modal lateral loads; b) tensile strain diagram at ultimate load step of uniform Y pushover analysis

The seismic assessment of the water tower no. 1 is performed, according to [5], in terms of displacement capacity based on the ADSR spectrum. Uniform and modal lateral forces distributions, both $\mathrm{X}$ and $\mathrm{Y}$ directions, were adopted.

The safety verifications are reported in Figure 13.
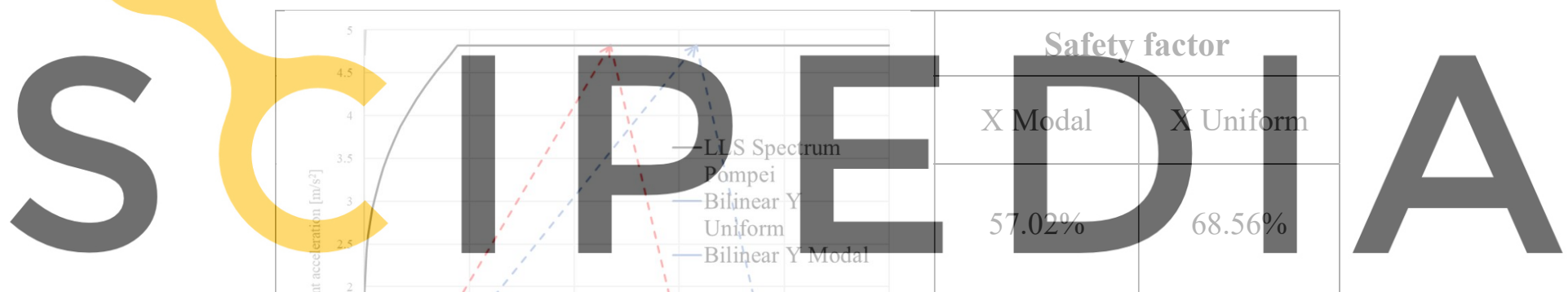

Register for free at https//www.scipedia.com to download the version without the watermark

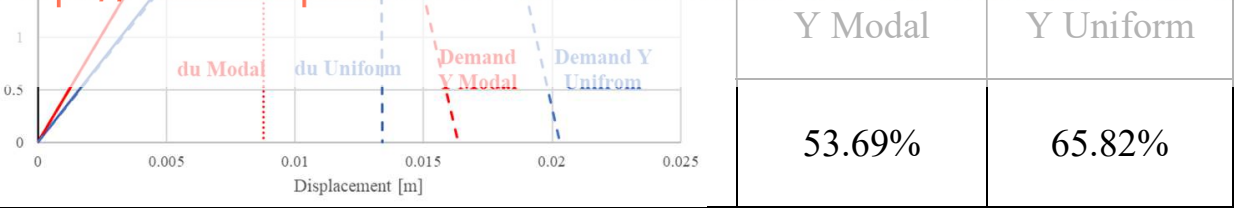

Figure 13. Safety verification procedure and safety factors.

\section{CONCLUSIONS}

The research presented within this paper aims at emphasizing the importance of a multidisciplinary approach to the structural and seismic vulnerability assessment of important archaeological structures in Pompeii (Italy). In-situ survey of geometry and crack pattern, historical evolution of the building and on-inspections represent the necessary preliminary steps, fundamental to define correctly all subsequent stages of the seismic evaluation. In particular the use of ambient vibration test and modal analysis was useful to update and calibrate numerical models, since simple estimations from typical values of the building materials (e.g. clay bricks, tuff, limestone, etc.) could lead to an overestimation of the global stiffness. Such a non-destructive test is highly desirable for heritage structures and monuments since it provides 
fairly accurate results without having to impose any potential harm to their integrity.

The limit analysis method (macroelements approach) proved to be a reliable tool for the seismic assessment, requiring specific parameters (geometry, damage pattern, etc.), easily derivable from on-site inspections. The implementation of elastic numerical models can be useful to determine the dynamic properties of the structure and perform an initial assessment of the seismic capacity. The integration with more advanced analysis, implementing non-linear constitutive laws of materials, is still a key issue in the correct evaluation of masonry structures.

A brief comparison between the outcomes of kinematic analysis and pushover analysis for WT no. 1 makes clear that the latter one is generally more conservative than the former, as already noticed in [3]. Actually, the seismic verification is successfully passed according to kinematic overturning mechanism, while, according to FE, the displacement capacity of the tower is not enough for seismic demand.

The combined application of global (numerical models) and local (limit analysis) analyses of the response prove to be the correct way to define the most vulnerable structural elements and identify the main structural deficiencies of the water towers.

\section{REFERENCES}

[1] C. Ohlig (2001), De aquis Pompeiorum: das Castellum Aquae in Pompeii: Herlunft, Zuleitung und Verteilung des Wassers, Nimègue, 2001.

[2] F. Lorenzoni, M.R. Valluzzi, M. Salvalaggio, A. Minello, C. Modena (2017), Operational modal analysis for the characterization of ancient water towers in Pompeii, In Procedia Engineering, Volume 199, 2017, Pages 3374-3379, ISSN 1877-7058, https://doi.org/10.1016/j.proeng.2017.09.446

[3] A. Pappas, F. da Porto, C. Modena, H. Dessales, "Seismic vulnerability assessment of ancient water towers in Pompeii with kinematic, finite element and discrete element analysis”. In: ANIDIS 2013 - L'Ingegneria Sismica in Italia, (2013)

[4] DIANA FEA, DIANA 10.3 Finite Element Analysis User Guide, TNO DIANA BV, Delft, 2019

[5] D. M. 17 gennaio 2018, Norme tecniche per le costruzioni, Ministero delle Infrastrutture e dei Trasporti, 2018 (in Italian)

[6] T. L. Heres, "The structures related to the water supply of Pompeii: materials and chronology," Mededelingen Van Het Nederlands Instituut Te Rome, vol. 51/52, pp. 42-61, 1992-1993.

[7] Dessales H. (2008), "D'eau et de pierre. Recherches des laboratoires d'archéologie et de géologie de l'Ecole normale supérieure sur le Réseau hydraulique de Pompéei et son bâti.," 2008.

[8] J. Carlut, H. Dessales, \& J. de Sigoyer (2012). D'eau et de pierre: le reseau hydraluique de Pompei et son bati. Paris, France (in French)

[9] Bowles J. E., Foundation analysis and design, McGraw-Hill, USA, 1996, pp. 121-127, 501509

[10] Elyamani A., Integrated monitoring and structural analysis strategies for the study of large historical construction. Application to Mallorca cathedral. PhD Thesis. Director. Roca P., Universitat Politecnica de Catlunya, 2015 